\title{
Alzheimer's disease and the relationship between silicon and aluminium in water supplies in northern England
}

\author{
G A Taylor, A J Newens, J A Edwardson, D W K Kay, D P Forster
}

\section{MRC Neurochemical Pathology Unit, Newcastle upon Tyne G A Taylor D W K Kay \\ J A Edwardson}

Centre for Health University of

Newcastle upon Tyne,

Newcastle upon Tyne

A J Newens

School of Health Care Sciences,

University of

Newcastle

Medical School,

Newcastle upon Tyne,

NE2 4HH

D P Forster

Correspondence to:

Dr D P Forster.

Accepted for publication November 1994

I Epidemiol Community Health 1995;49:323-324 Services Research

A recent case-control study failed to show any statistically significant relationship between presenile dementia of the Alzheimer type (PDAT) and exposure to aluminium in drinking water, tea, or medicines. ${ }^{1}$ However, Birchall has argued, on geochemical grounds, that in soft water areas silicic acid (dissolved silicon) will be low and the water may contain aluminium because of acidity or the addition of aluminium salts to flocculate organic matter in peaty waters. On the other hand, in hard water areas where silicic acid is high, the water will be low in aluminium. ${ }^{2}$ Moreover, silicon determines the bioavailability of all sources of dietary aluminium. ${ }^{34}$ In this study, therefore, the concentration of both dissolved silicon and aluminium in current water supplies was examined to determine whether an inverse relationship exists between dissolved silicon and aluminium.

Methods: Water samples were collected between the 23 June and 15 July, 1993, based on the list of addresses of 109 cases and 109 controls in a previous study of PDAT through-

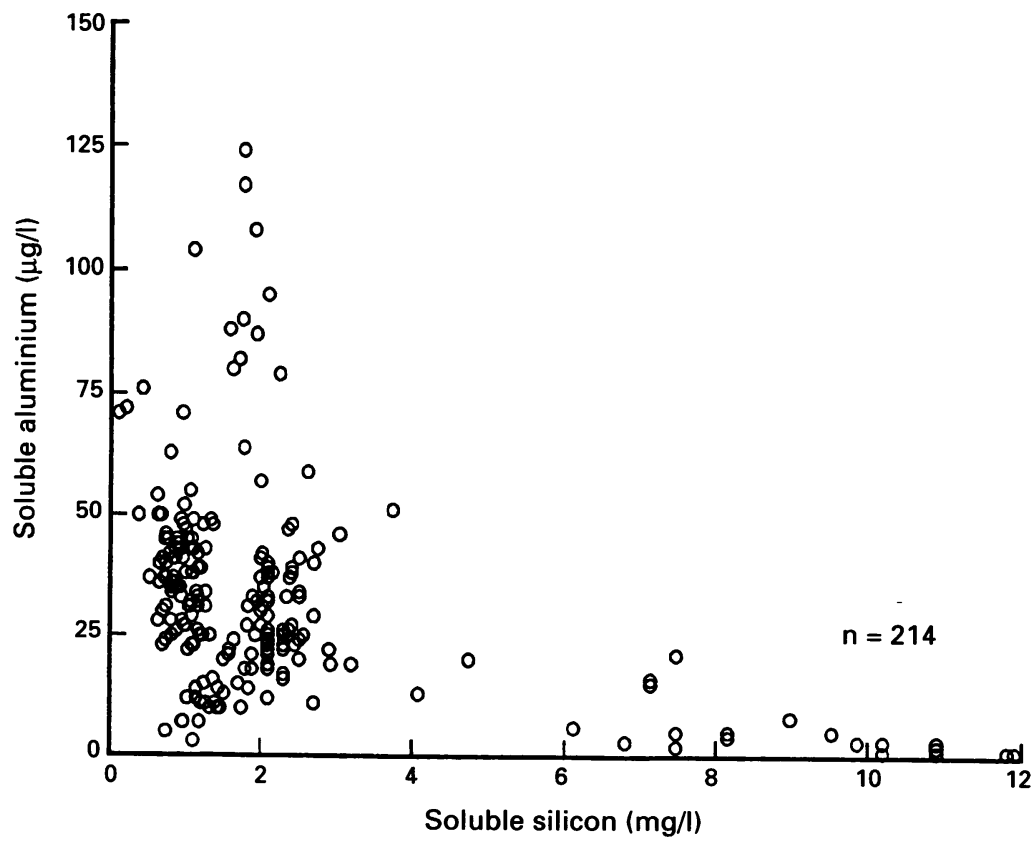

out the northern health region. ${ }^{1}$ These addresses were the location at which the case of PDAT had lived longest during the 10 years before the onset of symptoms of dementia (and the equivalent in the control). All cold water samples were collected in silicon free containers by a single investigator (GT), blind to knowledge of whether a case or control had lived there, after the tap had been run for 30 seconds. The water samples were randomised and both aluminium and silicon were measured using a modification of a previous method by graphite furnace atomic absorption spectrometry using an AS40 autosampler, HGA500 furnace 3030 spectrophotometer, and pyro coated L'vov tubes. $^{5}$

Results: Water samples were obtained for 214 of the $218(98.2 \%)$ addresses of cases and controls. The inverse relationship between dissolved aluminium and dissolved silicon is shown in the figure. Spearman's rank order correlation coefficient between soluble silicon and soluble aluminium was $-0.43(\mathrm{p}<0.001)$.

No historical data on silicon in water were available to apply to our cases of PDAT and matched controls. We therefore compared the case-control pairs for which we had data $(n=$ 105) for current levels of silicon at their address, based on these water samples. Using the Wilcoxon matched pairs signed-ranks test, soluble silicon values in the cases were not significantly different than in the controls $(p=0 \cdot 65)$. Similarly, the dissolved aluminium values in current water samples, based on the addresses of cases and controls, were not significantly different $(p=0 \cdot 60$, Wilcoxon matched pairs signedranks test). The odds ratio in the case-control pairs, for the threshold value of $3 \mathrm{mg} / \mathrm{l}$ $(100 \mu \mathrm{mol} / \mathrm{l})$ of soluble silicon or above, was calculated as 0.8 (95\% confidence interval $0.34,1.83$ ), which was not significant at the $5 \%$ level.

Discussion: The study of water samples showed an inverse relationship between soluble silicon and soluble aluminium, thus supporting the hypothesis proposed by Birchall. ${ }^{2}$ Birchall also suggested that a threshold level of 
$100 \mu \mathrm{mol} / 1$ (about $3 \mathrm{mg} / \mathrm{l}$ ) of soluble silicon is necessary to protect against the absorption of aluminium, that is all forms of aluminium in the diet. ${ }^{4}$ Unfortunately, we did not have historical data on silicon levels in water before the onset of dementia. We therefore applied the current silicon levels to our case-control pairs and found a non-significant OR of 0.8 based on the postulated protective level of $3 \mathrm{mg} / 1$ of dissolved silicon in water. The weight that can be placed on this result is debatable given that the proposed protective factor was measured after the disease onset, albeit based on the address before the onset of dementia. However, silicon levels in the same water source are relatively stable with time, although the source of water for a particular area may have been changed. Additionally, relatively few of the samples had a silicon concentration of $3 \mathrm{mg} / \mathrm{l}$ or above in order to test the threshold hypothesis of silicon in water.

Silicon determines the bioavailability of all dietary exposures to aluminium. It is availability rather than simple exposure which is important if aluminium is causally involved in $\mathrm{AD}$; we therefore suggest that the possible preventive role of silicon in PDAT requires further investigation. For example, the incidence rates of $\mathrm{AD}$ in areas in which the concentration of silicon is high ( $3 \mathrm{mg} / \mathrm{l}$ or above in water) could be compared with those in areas of low silicon values.

1 Forster DP, Newens AJ, Kay DWK, Edwardson JA. Risk factors in clinically diagnosed presenile dementia of the Alzheimer type: a case-control study. 1994 f Epidemiol Community Health 1995;49:253-58.

2 Birchall JD, Chappell JS. Aluminium, water chemistry, and Alzheimer's disease. Lancet 1989;i:953.

3 Edwardson JA, Moore PB, Ferrier IN, Lilley JS, Newton GWA, Barker J et al. Effect of silicon on gastrointestinal absorption of aluminium. Lancet 1993;342:211-2.

4 Birchall JD. The role of silicon in aluminium toxicity. In: Lord Walton of Detchant ed. Alzheimer's disease and the environment. London: Royal Society of Medicine, 1991. Round Table Series 26.

5 Parkinson IS, Ward MK, Kerr DNS. A method for the routine determination of aluminium in serum and water by flameless atomic absorption spectrometry. Clinica Chimica Acta 1982;125:125-33.

\title{
Asthma history and sociodemographic characteristics in elderly French people
}

\author{
Chakib Nejjari, Jean François Tessier, Pascale Barberger-Gateau, Luc Letenneur, \\ Jean François Dartigues, Roger Salamon
}

Asthma is a disabling chronic disease, especially in elderly people in whom prevention of the loss of autonomy becomes very important. ${ }^{1}$ Recent data have also suggested that mortality related to asthma has increased over the past 10 years in both Britain and France, particularly in the elderly. ${ }^{2}$ There are, however, few epidemiological data on asthma in this group.

This was a cross sectional study. Based on a cohort of subjects aged 65 and over (Paquid cohort), we aimed to investigate the prevalence and sociodemographic characteristics of self reported asthma in this population.

\section{INSERM U 330,}

Université de

Bordeaux II, 146 rue

Léo-Saignat, F 33076

Bordeaux Cedex,

France

C Nejjari

J F Tessier

P Barberger-Gateau

L Letenneur

J F Dartigues

R Salamon

Correspondence to:

Dr J F Tessier.

Accepted for publication January 1995

f Epidemiol Community Healt 1995;49:324-325
Methods: Paquid is a cohort of 3777 dwellers, representative of the population aged 65 and over in two administrative areas of south western France (Gironde and Dordogne). Baseline data were collected in 1988-89. The Paquid questionnaire included sociodemographic characteristics: age (in years), sex, main lifetime occupation (housewives, farm workers, blue collar workers, and white collar workers), smoking status (current, former, and never smokers), and many variables on health status, disability, cognitive performance, and medication. Details of the Paquid methodology have been published elsewhere. ${ }^{3}$
Data for this study were taken from the third year of the follow up. A total of 2406 subjects (63.7\% of the initial sample) were involved. Asthma identification was based on two questions: (1) "Have you ever had asthma?" and (2) "Did you have at least one asthma attack in the last 12 months?" Subjects were categorised according to their smoking history.

The prevalence of asthma was evaluated in relation to sex, smoking status, and lifetime occupation. An association between former work and asthma was determined by logistic regression analysis. The dependent variable was asthma history (coded 1 versus 0 ). Explanatory variables were age (in years), sex (women versus men), smoking history (current smokers, and former smokers versus never smokers), and former work (housewives, farm workers, and blue collar workers versus white collar workers).

Results: Of 2406 subjects, 2355 (97.5\%) responded to the questions on asthma symptoms (979 men and 1376 women). A total of 144 subjects $(6 \cdot 11 \%)$ reported asthma and 58 $(40.2 \%)$ of them at least one attack in the last 12 months. The mean (SD) age was lower in subjects with a history of asthma compared 